\title{
Impact of Magnetic Field Strength and Receiver Coil in Ocular MRI: A Phantom and Patient Study
}

\author{
Wertigkeit von Feldstärke und Empfangsspule bei der MRT des Auges: \\ Untersuchungen am Phantom und bei Patienten
}

Authors

Affiliations
K. Erb-Eigner ${ }^{1}$, C. Warmuth ${ }^{1}$, M. Taupitz ${ }^{1}$, G. Willerding ${ }^{2}$, E. Bertelmann ${ }^{2}$, P. Asbach ${ }^{1}$

Department of Radiology, Charité - Universitätsmedizin Berlin, Germany

2 Department of Ophthalmology, Charité - Universitätsmedizin Berlin, Germany
Key words

- eye

- MR-imaging

- technical aspects

eingereicht 18.1.2013

akzeptiert 13.5 .2013

Bibliography

DOI http://dx.doi.org/

10.1055/s-0033-1335796

Published online: 25.7.2013

Fortschr Röntgenstr 2013; 185 :

830-837 @ Georg Thieme

Verlag KG Stuttgart - New York .

ISSN 1438-9029

\section{Correspondence}

Dr. Katharina Erb-Eigner

Radiologie, Charité

Hindenburgdamm 30

12203 Berlin

Germany

Tel.: ++ 49/30/84453041

Fax: ++ 49/30/4507527953

katharina.erb@charite.de

\section{Abstract \\ $\nabla$}

Purpose: Generally, high-resolution MRI of the eye is performed with small loop surface coils. The purpose of this phantom and patient study was to investigate the influence of magnetic field strength and receiver coils on image quality in ocular MRI.

Materials and Methods: The eyeball and the complex geometry of the facial bone were simulated by a skull phantom with swine eyes. MR images were acquired with two small loop surface coils with diameters of $4 \mathrm{~cm}$ and $7 \mathrm{~cm}$ and with a multi-channel head coil at 1.5 and 3 Tesla, respectively. Furthermore, MRI of the eye was performed prospectively in 20 patients at 1.5 Tesla $(7 \mathrm{~cm}$ loop surface coil) and 3 Tesla (head coil). These images were analysed qualitatively and quantitatively and statistical significance was tested using the Wilcoxon-signed-rank test (a p-value of less than 0.05 was considered to indicate statistical significance).

Results: The analysis of the phantom images yielded the highest mean signal-to-noise ratio (SNR) at 3 Tesla with the use of the $4 \mathrm{~cm}$ loop surface coil. In the phantom experiment as well as in the patient studies the SNR was higher at 1.5 Tesla by applying the $7 \mathrm{~cm}$ surface coil than at 3 Tesla by applying the head coil. Concerning the delineation of anatomic structures no statistically significant differences were found.

Conclusion: Our results show that the influence of small loop surface coils on image quality (expressed in SNR) in ocular MRI is higher than the influence of the magnetic field strength. The similar visibility of detailed anatomy leads to the conclusion that the image quality of ocular MRI at 3 Tesla remains acceptable by applying the head coil as a receiver coil.
Key Points:

- The smaller the coil and the closer to the object the higher the signal-to-noise ratio is.

- In ocular MRI, the influence of the coil on image quality is greater than the influence of the magnetic field strength.

- In ocular MRI, 3 Tesla can result in an acceptable image quality by using the head coil.

Citation Format:

- Erb-Eigner K, Warmuth C, Taupitz M etal. Impact of Magnetic Field Strength and Receiver Coil in Ocular MRI: A Phantom and Patient Study. Fortschr Röntgenstr 2013; 185 : $830-837$

\section{Zusammenfassung}

$\nabla$

Ziel: Das hochauflösende MRT des Auges wird im Allgemeinen mit kleinen ringförmigen Oberflächenempfangsspulen durchgeführt. Das Ziel dieser Studie war es, mittels Phantommessungen und Patientenuntersuchungen den Einfluss von Feldstärke und Empfangsspule auf die Bildqualität der MRT des Auges zu ermitteln.

Material und Methoden: Der Augapfel und die komplexe Geometrie des Gesichtsschädels wurden mit einem Schädelmodell mit Schweineaugen simuliert. MRT-Messungen wurden mit 2 kleinen Oberflächenringspulen mit den Durchmessern $4 \mathrm{~cm}$ und $7 \mathrm{~cm}$ und einer MehrkanalKopfspule bei jeweils 1,5 und 3 Tesla durchgeführt. Zudem wurde prospektiv bei 20 Patienten eine MRT des Auges bei jeweils 1,5 Tesla $(7 \mathrm{~cm}$ Oberflächenringspule) und 3 Tesla (Kopfspule) durchgeführt. Diese Bilddaten wurden qualitativ und quantitativ analysiert und statistisch ausgewertet (Wilcoxon-Rangsummen-Test, Signifikanzniveau 0,05).

Ergebnisse: Die Auswertung der Phantommessungen ergab das höchste mittlere Signal-zu- 
Rausch-Verhältnis (SNR) bei 3 Tesla mit der $4 \mathrm{~cm}$-Oberflächenringspule. Sowohl bei den Phantommessungen als auch bei den Patientenuntersuchungen ergab die Verwendung einer $7 \mathrm{~cm}$ Oberflächenringspule bei 1,5 Tesla ein höheres SNR als die Verwendung der Kopfspule bei 3 Tesla. Hinsichtlich der anatomischen Detailerkennbarkeit konnten jedoch keine signifikanten Unterschiede festgestellt werden.

Schlussfolgerung: Unsere Ergebnisse zeigen, dass bei der MRT des Auges der Einfluss der verwendeten Spule auf die Bildqualität (ausgedrückt als SNR) höher ist als der Einfluss der Feldstärke. Die konstante anatomische Detailerkennbarkeit lässt jedoch den Rückschluss zu, dass die Bildqualität der MRT des Auges bei 3 Tesla auch unter Verwendung der Kopfspule als Empfangsspule zu akzeptablen Ergebnissen führt.

\section{Introduction}

Magnetic resonance imaging (MRI) is the method of choice for the radiological imaging of the eye and has replaced computed tomography (CT) in many instances. In particular, the excellent soft tissue contrast and the absence of radiation exposure for the lenses, which are highly sensitive to X-ray radiation, are strong arguments for using ocular MRI [1 - 3]. CT of the eye and orbits, however, can play a major role in detecting foreign objects (glass particles [4]).

High-resolution ocular MRI is indicated for a wide range of routine clinical situations. For instance, unclear ophthalmoscopic findings such as vitreous opacity/hemorrhage as well as unclear retinal detachment, intraocular space occupations (e.g. uveal melanoma [5]), infectious diseases of the eye and rare developmental disorders or deformities of the eye (e.g.: staphyloma/coloboma [6]) demand dedicated imaging for finding signs of spreading and determining extraocular involvement. In this process, the planning of treatment (e.g. irradiation planning, planning surgical intervention) takes center stage, making high-quality MRI images especially important.

High-resolution ocular MRI is generally performed with small loop surface coils. Such coils have been used for years in MRI of the eyes and orbits: 1985 [7], 1986 (13 cm diameter) [8], 1988 (12 cm diameter) [9], 1991 (13.97 cm diameter or 5.5 inch) [10], 1996 (5 cm and $4 \mathrm{~cm})$ [11, 12] and 2008 $(4.7 \mathrm{~cm})$ [13].

In recent years, 3-Tesla MRI scanners have seen increased use in clinical practice. The advantage of the higher field strength has been demonstrated, for instance, in neuroradiological and uroradiological examinations as well as in examinations of the joints [14-18]. In the case of ocular MRI as well, initial studies at higher field strength (3 Tesla) showed a higher SNR [19]. However, the higher susceptibility to artifacts due to eye movement would appear to offset this advantage [20].

In addition to limited availability, the substantial effort required for precisely positioning and fixing the small loop coils represents a significant limitation of these surface coils in practice. The increasing use of 3-Tesla MRI equipment begs the question whether small loop surface coils continue to be necessary or whether an acceptable image quality can be achieved at 3 Tesla using the significantly more manageable head coil.
To our knowledge, no studies to date have systematically examined the influence of field strength and receiver coil on the image quality of ocular MRI.

The goal of this study was to ascertain the influence of field strength and receiver coil on ocular MRI using phantom measurements and patient examinations.

\section{Material and methods}

$\nabla$

\section{Phantom study}

MRI data acquisition and coils used

The orbits of an artificial model of an average sized human skull were filled with Vaseline to simulate orbital fat. Porcine eyes are frequently used as ex-vivo models for ophthalmological studies on cataracts, glaucoma and the retina [21]. Two fresh porcine eyes (origin: specialized butcher shop, Germany) were therefore inserted into the orbital fat of the model skull ( $\bullet$ Fig. 1). The small loop surface coils and the multi-channel head coil were placed on the phantom as described below in the usual manner employed for MRI examinations in patients.

A 1.5-Tesla MRT system with a maximum gradient amplitude of $33 \mathrm{mT} / \mathrm{m}$ and a maximum slew rate of $125 \mathrm{mT} / \mathrm{m} /$ ms (MAGNETOM Aera, Siemens Health Care, Erlangen) and 3-Tesla MRT system with a maximum gradient amplitude of $45 \mathrm{mT} / \mathrm{m}$ and a maximum slew rate of $200 \mathrm{~m} / \mathrm{T} / \mathrm{m} / \mathrm{ms}$ (MAGNETOM Skyra, Siemens Health Care, Erlangen) were on hand for the examination.

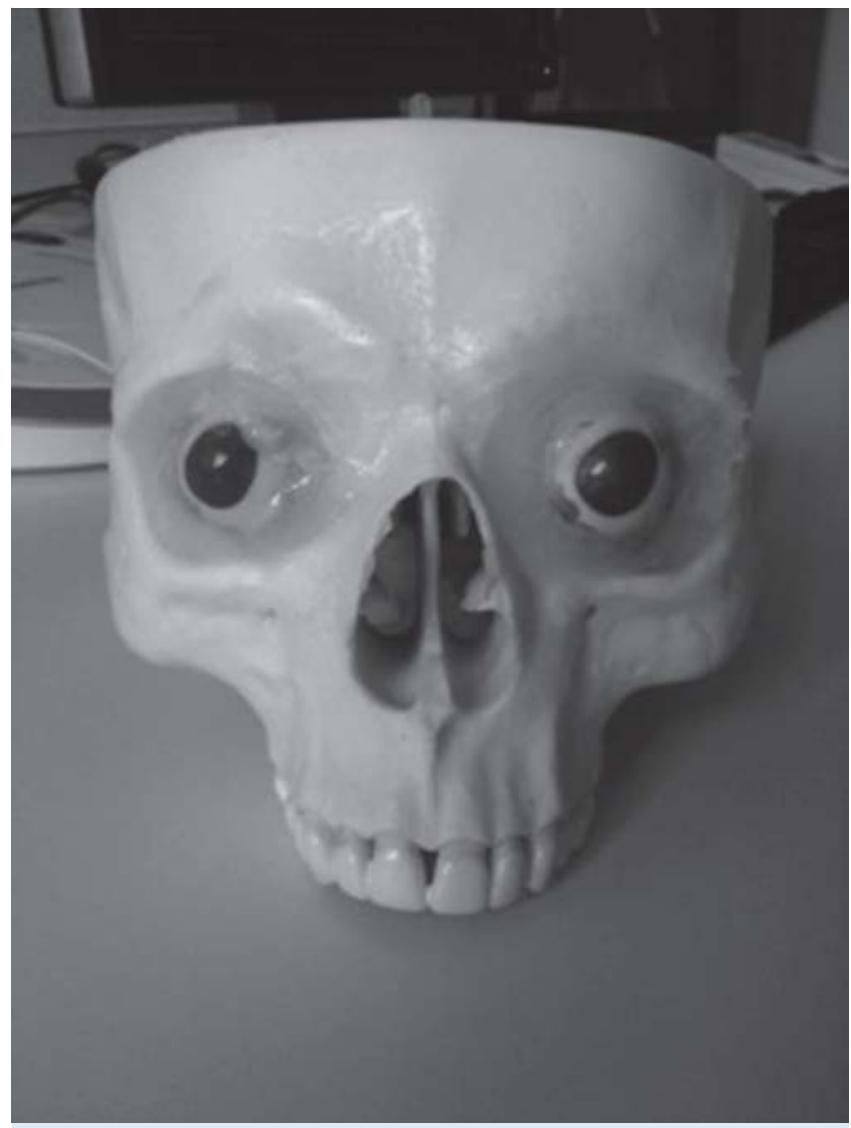

Fig. 1 Skull phantom with swine eyes. 
Tab. 1 Distances from the Region of Interest (ROI) to the surface.

\begin{tabular}{|l|l|}
\hline & distance to surface \\
\hline ROI superficial mesial & $17 \mathrm{~mm}$ \\
\hline ROI superficial temporal & $17 \mathrm{~mm}$ \\
\hline ROI deep temporal & $34 \mathrm{~mm}$ \\
\hline ROI deep mesial & $39 \mathrm{~mm}$ \\
\hline ROI orbital apex & $52 \mathrm{~mm}$ \\
\hline
\end{tabular}

Following the completion of a planning scan, a T2-weighted sequence was performed with acquisition parameters that were nearly identical at 1.5 and 3 Tesla: Repetition time (TR) $3000 \mathrm{~ms}$, echo time (TE) $68 \mathrm{~ms}$ ( 1.5 Tesla) and $65 \mathrm{~ms}$ (3 Tesla), matrix $512 \times 269$, field of view (FOV) $60 \times 80 \mathrm{~mm}$, slice thickness (ST) $1.5 \mathrm{~mm}, 1$ averaging (NEX), bandwidth (BW) $130 \mathrm{~Hz} /$ pixel (1.5 Tesla) and $220 \mathrm{~Hz} /$ pixel (3 Tesla).

The sequence was acquired twice consecutively and identically to facilitate measuring the noise using a subtraction image (subtraction method [22]). In total 5 slices were acquired.

The following receiver coils were available for both 1.5 Tesla and 3 Tesla:

- A 4-channel loop surface coil with a diameter of $4 \mathrm{~cm}$

- A 4-channel loop surface coil with a diameter of $7 \mathrm{~cm}$

- A 20-channel head coil

In our examinations, the porcine eye measured $21 \times 21 \times 16 \mathrm{~mm}(\mathrm{ML}, \mathrm{CC}, \mathrm{AP})$. While the human eye has similar dimensions to that of the porcine eye, it has a more spherical form and an average diameter of 21.5 to $24.95 \mathrm{~mm}$ (standard deviation $0.75 \mathrm{~mm}$ [23]). The distances from the ROIs (Regions of Interest) to the surface coil are summarized in 0 Table 1 to document the anatomical analogy to the human eye/orbit. The position of the model human skull in the head coil corresponded to the position of the skull in patient examinations.

\section{Quantitative image evaluation}

The signal-to-noise ratio (SNR) was ascertained for each measurement as follows: Two ROIs measuring $0.33 \mathrm{~cm}^{2}$ were placed in the vitreous body of the porcine eye. Three additional ROIs of the same size were placed in the Vaseline-filled orbits. Signal intensity (SI) was ascertained for each ROI, and the distances between the ROIs and the surface (coil) were documented. Noise was measured analogically on the subtraction images. The SNR was computed for each ROI using the following formula: SNR=average SI/ standard deviation of the noise. Finally, an average was calculated for all five ROIs.

\section{Patient study}

MRI data acquisition and coils used

Twenty patients between the ages of 33 and 69 (13 males, average age of 57.3 and 7 females, average age of 52.1) were consecutively included in the study after being referred to the ophthalmological clinic. The prerequisite for inclusion was the written declaration of consent to participate in the prospective study approved by the ethics committee. Each patient was examined using the 1.5 Tesla MRI system described above with 7-cm surface loop coil and then using the 3 Tesla MRI system with the 20-channel head coil during the same session. This study protocol $(7 \mathrm{~cm}$ loop surface coil at 1.5 Tesla and head coil at 3 Tesla) was selected, since a small surface coil is standard for imaging the eyes and 1.5 Tesla equipment is most readily available, making this surface coil and field strength combination certainly the most widely distributed.

Acquisition parameters were as follows:

1. 1.5 Tesla MRI:

- T1-weighted TSE sequence in axial slices: TR $264 \mathrm{~ms}$, TE $14 \mathrm{~ms}$, Matrix $256 \times 208$, FOV $81 \times 100 \mathrm{~mm}$, NEX 1 , BW $130 \mathrm{~Hz} /$ pixel, slice thickness $2 \mathrm{~mm}$, acquisition time 3:17 min.

- Axial T2-weighted 3 D TSE SPACE (sampling perfection with application optimized contrast using different flip angle evolutions) sequence: TR $350 \mathrm{~ms}$, TE $70 \mathrm{~ms}$, matrix $192 \times 156$, FOV $64 \times 79 \mathrm{~mm}$, NEX 1, BW $175 \mathrm{~Hz}$ pixel, slice thickness $1 \mathrm{~mm}$, acquisition time 5:04 min.

2. 3 Tesla MRI:

- T1-weighted TSE sequence in axial slices: TR $650 \mathrm{~ms}$, TE $9.1 \mathrm{~ms}$, matrix $256 \times 208$, FOV $81 \times 100 \mathrm{~mm}$, NEX 1 , BW $390 \mathrm{~Hz} /$ pixel, slice thickness $2 \mathrm{~mm}$, acquisition time 03:04:00 min.

- T2-weighted 2D TSE sequence in axial slices: TR $3500 \mathrm{~ms}$, TE $69 \mathrm{~ms}$, matrix $192 \times 156$, FOV $64 \times 79 \mathrm{~mm}$, NEX 1, BW $225 \mathrm{~Hz} /$ pixel, slice thickness $1 \mathrm{~mm}$, acquisition time 3:35 min.

\section{Quantitative analysis}

The non-contrast enhanced T1-weighted TSE sequence was used to compute SNR. Two ROIs measuring $0.6 \mathrm{~cm}^{2}$ were placed in the vitreous body. The SI was ascertained for each ROI and the distances between the ROIs and surface (coil) were documented. The SI of both ROIs was averaged. An additional ROI was placed in frequency encoding direction in the surrounding air outside the vitreous body to ascertain noise. The SNR was computed using the formula SNR = average SI/standard deviation of the noise. Finally, an average was calculated from the SNRs (vitreous body) of the examined patients.

\section{Qualitative analysis}

The subjective image quality was assessed based on the degree of visibility of anatomical structures. Two radiologists experienced in imaging the eyes unanimously issued the following statements based on a 4-point Likert scale (agree = $1 /$ agree somewhat=2 / disagree somewhat=3 / disagree $=4$ ):

- The ciliary body is clearly visible in the T2-weighted sequence.

- The optic nerve sheath is clearly visible in the T2-weighted sequence.

- Sclera and choroid are clearly differentiated in the T1weighted sequence.

- There are no motion-induced artifacts in the T1-weighted sequence.

- There are no motion-induced artifacts in the T2-weighted sequence.

An average was computed from the results.

\section{Statistics}

The quantitative SNR measurements as well as the results of the qualitative analysis were tested for statistically significant differences using the non-parametric Wilcoxonsigned-rank test. Significance was set at $5 \%$. 


\section{Results}

$\nabla$

\section{Phantom study}

Analysis of phantom image data showed maximum SNR (13.1) at 3 Tesla with the smallest loop surface coil $(4 \mathrm{~cm})$. As expected, the lowest SNR (2.3) was achieved at 1.5 Tesla with the head coil. Using a $7 \mathrm{~cm}$ loop surface coil at 1.5 Tesla yielded a higher SNR (5.8) than using the head coil as receiver coil at 3 Tesla (3.2). While a relative difference in SNR between superficial and deep regions was observed when the small loop surface coils were used, the SNR remained constant over the entire orbits when the head coil was used. Overall, SNR of the deep regions was found to be relatively unaffected by field strength and coil ( $\bullet$ Fig. 2 ). The computed SNRs are summarized in $\bullet$ Table 2. $\odot$ Fig. 3 shows the porcine eye with the small loop surface coil $(4 \mathrm{~cm}$ and $7 \mathrm{~cm}$ ) and the head coil being used as well as at different field strengths (1.5 and 3 Tesla).

\section{Patient study}

Ocular MRI was performed on 19 patients with uveal melanoma that had already been detected by an ophthalmoscope. In the case of one patient, ocular MRI was performed to further clarify a slowly progressing exophthalmos. A large orbital hemangioma was found to be the cause of the exophthalmos, and the optic nerve sheath could not be evaluated due to the compression resulting from the space occupation. One patient's uveal melanoma was found to be hemorrhaging. The susceptibility artifacts caused by blood breakdown products make it impossible to measure the SI in the vitreous body. In one patient, the vitreous body had been replaced with oil, so that the SI thereof could not be ascertained.

The qualitative evaluation of 19 patients with uveal melanoma (optic nerve sheath in 18 patients) with regard to the visibility of anatomical details (ciliary body, optic nerve sheath differentiability between sclera and choroid) yielded no significant differences $(p>0.05)$ ( $($ Table 3 ) when using

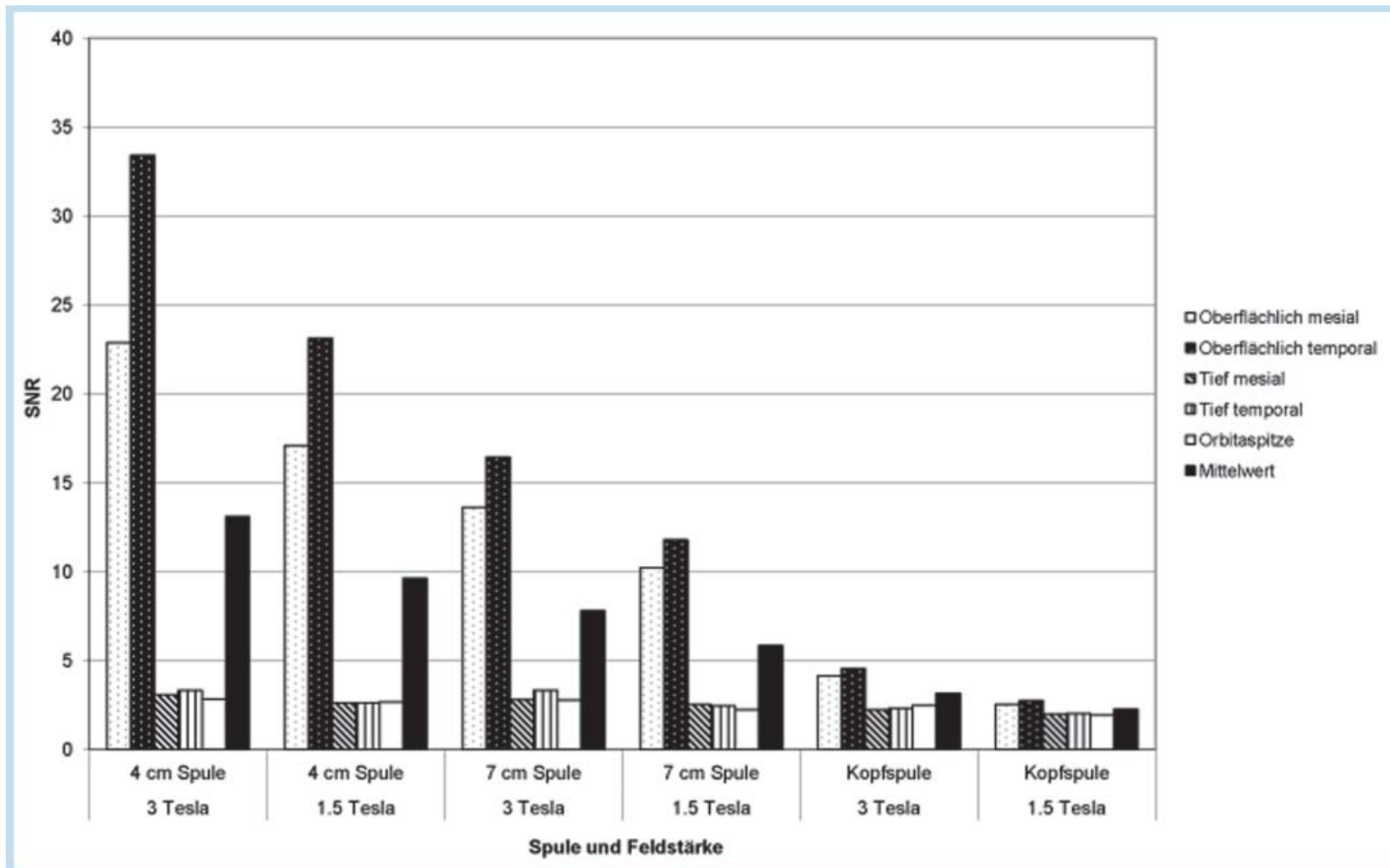

Fig. 2 The SNR in the superficial ROIs decreases by increasing coil size and lower field strength. The SNR in deep regions remained relatively constant using various coils and a different field strength.

\begin{tabular}{|c|c|c|c|c|c|c|}
\hline \multirow{2}{*}{$\begin{array}{l}\text { field strength } \\
\text { coil }\end{array}$} & \multicolumn{3}{|c|}{ 1.5 Tesla } & \multicolumn{3}{|c|}{3 Tesla } \\
\hline & $4 \mathrm{~cm}$ & $7 \mathrm{~cm}$ & head coil & $4 \mathrm{~cm}$ & $7 \mathrm{~cm}$ & head coil \\
\hline ROI superficial mesial & 17.1 & 10.2 & 2.5 & 22.9 & 13.6 & 4.1 \\
\hline ROI superficial temporal & 23.1 & 11.8 & 2.8 & 33.4 & 16.4 & 4.6 \\
\hline ROI deep mesial & 2.6 & 2.5 & 2.0 & 3.1 & 2.8 & 2.2 \\
\hline ROI deep temporal & 2.6 & 2.5 & 2.0 & 3.3 & 3.3 & 2.3 \\
\hline ROI orbital apex & 2.7 & 2.2 & 1.9 & 2.8 & 2.8 & 2.5 \\
\hline average & 9.6 & 5.8 & 2.3 & 13.1 & 7.8 & 3.2 \\
\hline
\end{tabular}

Tab. 2 SNRs ascertained in the phantom measurements in the respective ROIs. 

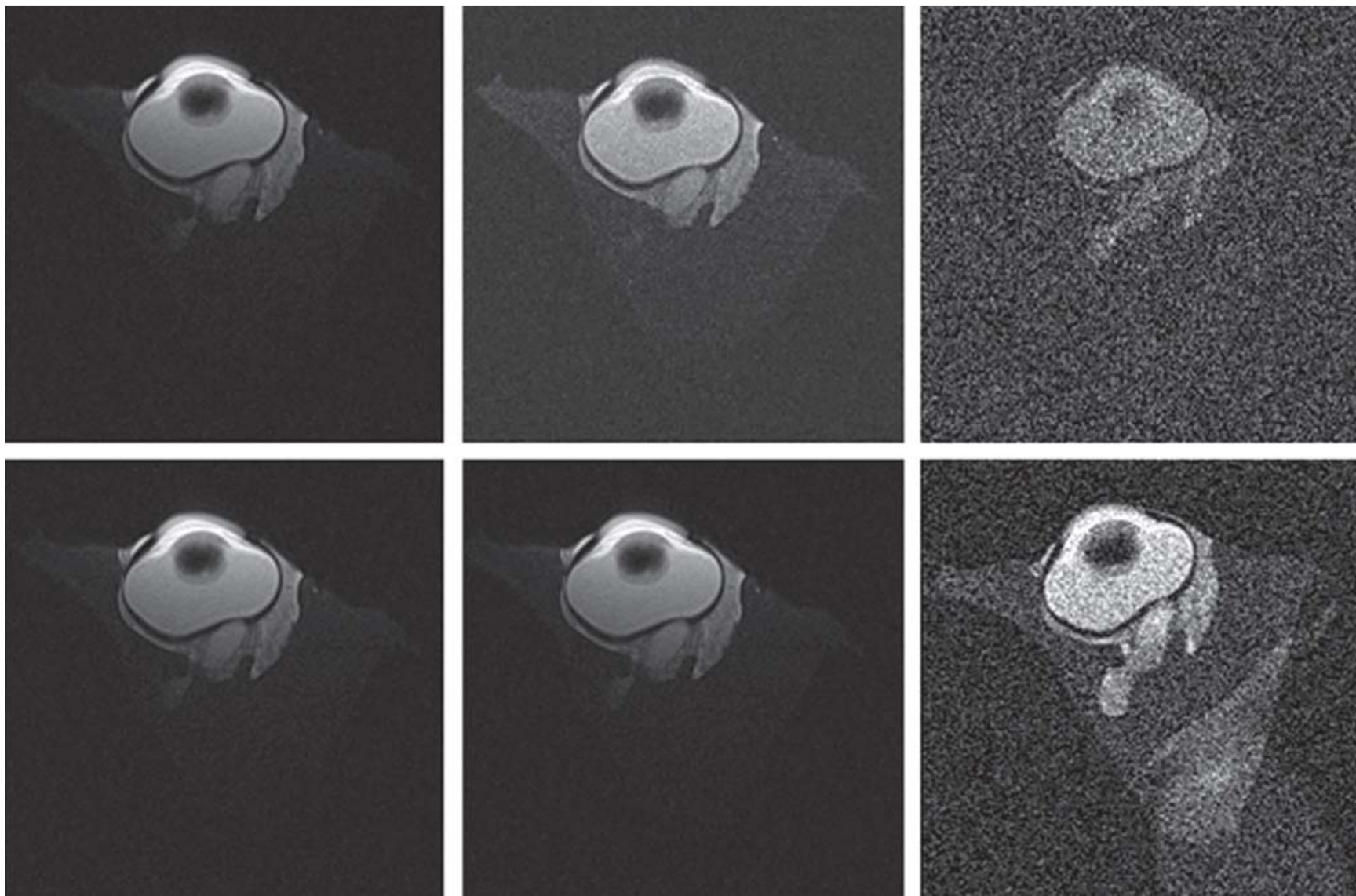

Fig. 3 MRI of the swine eye using the small surface ring coil of $4 \mathrm{~cm}$ in diameter (left), $7 \mathrm{~cm}$ in diameter (center) and the head coil (right) and at different field strengths: 1.5 Tesla (top) and 3 Tesla (below).

\begin{tabular}{|c|c|c|c|}
\hline & \multirow{2}{*}{$\begin{array}{l}1.5 \text { Tesla/7 cm coil } \\
\text { average }\end{array}$} & \multicolumn{2}{|c|}{3 Tesla/head coil } \\
\hline & & average & p-value \\
\hline $\begin{array}{l}\text { the ciliary body is clearly visible in the T2-weighted } \\
\text { sequence. }\end{array}$ & 1.6 & 1.7 & 0.49 \\
\hline $\begin{array}{l}\text { the optic nerve sheath is clearly visible in the } \\
\text { T2-weighted sequence. }\end{array}$ & 1.7 & 1.6 & 0.608 \\
\hline $\begin{array}{l}\text { the sclera and choroid are clearly differentiated in the } \\
\text { T1-weighted sequence. }\end{array}$ & 1.2 & 1.2 & 1.0 \\
\hline $\begin{array}{l}\text { there are no motion-induced artifacts in the T1- } \\
\text { weighted sequence. }\end{array}$ & 1.4 & 1.2 & 0.157 \\
\hline $\begin{array}{l}\text { there are no motion-induced artifacts in the T2- } \\
\text { weighted sequence. }\end{array}$ & 1.6 & 1.7 & 0.763 \\
\hline
\end{tabular}

Tab. 3 Qualitative analysis of image data sets of 19 patients (concerning the optic nerve sheath of 18 patients) using a Likert-scale (agree $=1 /$ agree somewhat $=2 /$ somewhat disagree $=3 /$ disagree $=4$ ) by two experienced radiologists in consensus.

the $7 \mathrm{~cm}$ loop surface coil at 1.5 Tesla and the head coil at 3 Tesla. In addition, there was no significant $(p>0.05)$ difference in terms of artifacts caused by eye movement, thereby establishing the comparability of the two MRI examinations ( Table 3). Fig. 4 shows an example of a patient with the $7 \mathrm{~cm}$ loop surface coil being used at 1.5 Tesla and the 20-channel head coil being used at 3 Tesla.

The quantitative evaluation of all usable image data sets $(\mathrm{n}=18)$ showed that there was a significantly $(\mathrm{p}<0.05)$ higher SNR (20.1) when a $7 \mathrm{~cm}$ loop surface coil was used than when the head coil was used as receiver coil at 3 Tesla (12.8).

\section{Discussion \\ $\nabla$}

A high SNR can be invested in a high spatial resolution and is thus generally used as a criterion for image quality [22]. In this study, the SNR for ocular MRI was systematically examined using loop surface coils and multi-channel head coils as well as different field strengths. In purely physical terms, magnetization increases linearly with field strength. Because the relaxation times also increase with field strength and the greater chemical shift, if any, requires higher bandwidths, the SNR benefits are lower depending on the sequence used [24]. 

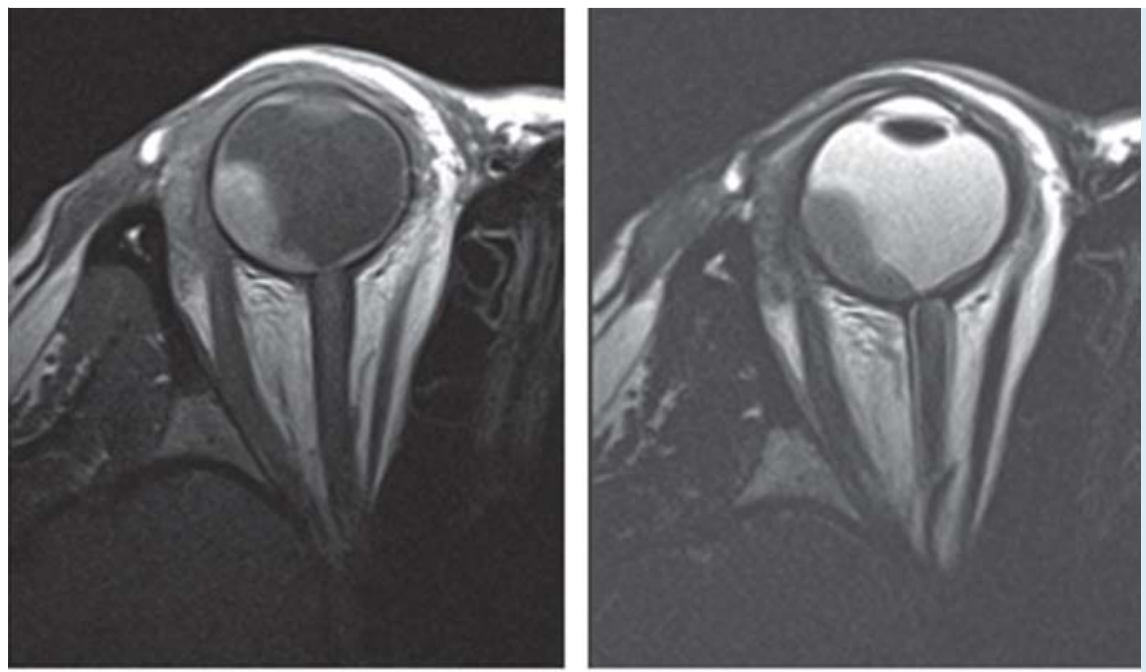

Fig. 4 A 42 year old female patient with temporal localized ocular melanoma in the right eye and retinal detachment close to the optic disc. T1-weighted sequences (left) and T2-weighted sequences (right), acquisition with the $7 \mathrm{~cm}$ surface coil at 1.5 Tesla (top) and with the 20 -channel head coil at 3 Tesla (bottom).
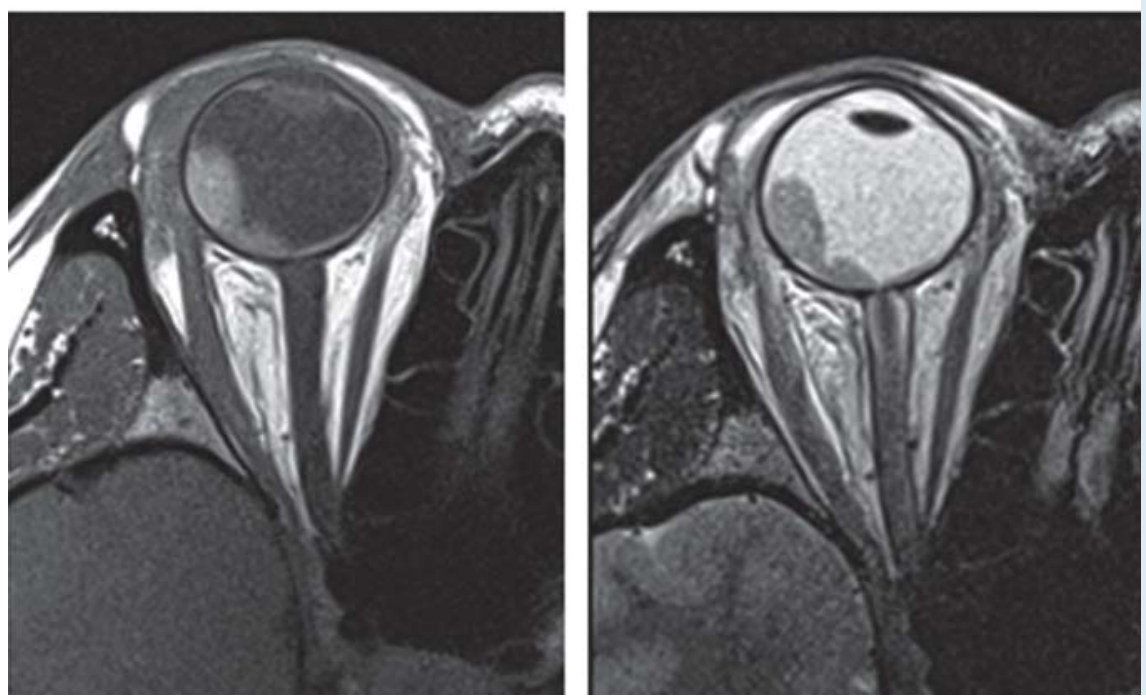

The results of the phantom measurement show that coil selection has a greater influence on SNR than field strength in the superficial regions. While the SNR in the superficial region is most strongly influenced by coil size and field strength, SNR in deep regions remains relatively constant when different coils and field strengths are used. These results have an influence on coil selection according to clinical objective. If a pathological process is expected in the anterior region of the orbit, then it is advisable to use a small surface coil. If, however, the pathology is expected in the posterior orbit, then optimal image quality can be achieved using the head coil.

The SNR of the superficial regions (11.0) ascertained with the phantom when using the $7 \mathrm{~cm}$ loop surface coil at 1.5 Tesla was 2.5 times higher than the SNR (4.4) ascertained when using the head coil at 3 Tesla. Among the results yielded from the patient measurements, this difference factor was 1.6 (average SNR 1.5 Tesla/7 cm loop surface coil=20.1 versus 3 Tesla/head coil $=12.9$ ). It is possible that the small size of the phantom (and thus lower coil proton load) resulted in a proportionally lower SNR than could have actually been achieved with the head coil, since the head coil is optimized for the measurement of an entire head (and thus a higher coil load). To keep the differences in the positioning of the loop surface coils as potential influencing factors to an absolute minimum, the $7 \mathrm{~cm}$ loop surface coil was used instead of the $4 \mathrm{~cm}$ coil, since the latter has an even significantly smaller field of measurement, thus making the positioning thereof more critical.

However, the results of the patient examinations demonstrated that in terms of the detectability of anatomical details (ciliary body, optic nerve sheath, differentiability between sclera and choroid), there were no significant differences between using the $7 \mathrm{~cm}$ loop surface coil at 1.5 Tesla and using the head coil at 3 Tesla. For practical considerations, however, the head coil is significantly more manageable and easier to use. The smaller loop surface coils, in contrast, must be fixed onto the patient's face, which is tolerated to varying degrees. Slippage of loop surface coils during measurement must absolutely be avoided, since even minimal malpositioning significantly changes regional illumination and SNR is reduced in the non-optimally illuminated regions. Achieving acceptable image quality using the head coil exclusively should thus be regarded as desirable.

Those ocular movements that are difficult to arbitrarily influence and the resulting artifacts they produce play an additional significant role in the imaging of the eye. To minimize eye movement, the 19 patients with uveal melanoma received retro-/ peribulbar anesthesia briefly before undergoing ocular MRI. The patient with the orbital hemangioma 
did not receive anesthesia given the risk of perforating the space occupation. The literature, however, also discusses less invasive approaches such as the arbitrary fixing of a point while using very brief sequences [25] as well as inserting pauses within the sequences specifically designed for imaging the eye [26]. In this study performed primarily with retro-/peribulbar anesthesia, no significantly stronger artifacts were observed at 3 Tesla compared to 1.5 Tesla.

Several articles have already dealt with imaging the eyes at higher field strengths $[19,20]$. The excellent image quality of MR-microscopy at a field strength of 7.1 Tesla was introduced in ex-vivo examinations of human eyes as well as in in-vivo examinations on animals [27]. To date there have been in vivo examinations of the eye at 7 Tesla $[28,29]$. Because, however, only a small number of clinical 7 Tesla fullbody MRI system are currently in operation, ocular imaging must be performed at lower field strength at most centers. The higher susceptibility artifacts expected at higher field strength were not demonstrated in our examinations with regard to the subjectively evaluated image quality.

The interpretation of our results faces certain limitations: In our phantom study T2-weighted sequences were used because the anatomy of the eye has better visibility in T2weighting, facilitating a more exact localization of ROI. The T1-weighted sequences selected in our patient study play, however, an important role in routine clinical practice. While the influence of contrast agent on image quality in T1-weighted sequences was not examined in our study, it is important when investigating tumor growth (e.g. extraocular growth).

In our patient study, we strove to keep the sequence parameters for the measurements performed at 1.5 and 3 Tesla as comparable as possible. While spatial resolution was kept identical for the sequences (FOV, matrix, slice thickness), TR, TE and bandwidth were adapted to the particular field strength. In particular, TR had to be extended at 3 Tesla due to the higher specific absorption rate (SAR). These differences in TR, TE and bandwidth at different field strengths have an influence on image quality and may thus also have an influence on SNR in our study. Our study also assessed the visibility of details in fine anatomic structures, yet not the visibility of pathological structure (e.g. extraocular tumor growth, etc.). Furthermore, only the image quality of the $7 \mathrm{~cm}$ loop surface coil at 1.5 Tesla and the head coil at 3 Tesla was examined using actual patients. Other coil/field strength combinations were observed only in the phantom and not on the patient cohort. The results of our studies have only limited applicability to children given the smaller anatomy.

\section{Conclusion}

$\nabla$

Our results show that the loop surface coil has a greater influence than field strength on image quality (expressed as SNR) in ocular MRI. However, this improvement in SNR facilitated by the small loop surface coil is observed only for the anterior structures of the eye (e.g. ciliary body). The constant visibility of anatomical detail leads, however, to the conclusion that the image quality of ocular MRI at 3 Tesla yields acceptable results even when only the head coil is used as receiver coil.

\section{Acknowledgement}

$\nabla$

This manuscript is dedicated to Professor Bernd Hamm for his 60th birthday.

\section{References}

1 Keil B, Wulff J, Schmitt R et al. Schutz der Augenlinse in der Computertomografie - Dosisevaluation an einem antropomorphen Phantom mittels Thermolumineszenzdosimetrie und Monte-Carlo-Simulationen. Fortschr Röntgenstr 2008; 180: 1047-1053

2 Spira D, Ernemann $U$, Schulze $M$ et al. Bildgebende Diagnostik von Orbitatumoren. Fortschr Röntgenstr 2009; 181: 925-927

3 Lemke AJ, Kazi I, Landeck LM et al. Differenzialdiagnostik intrakonaler orbitaler Raumforderungen unter Verwendung der hochauflösenden MRT mit Oberflächenspulen anhand von 78 Patienten. Fortschr Röntgenstr 2004; 176: 1436-1446

4 Hoffstetter P, Friedrich C, Framme C et al. Nachweismöglichkeit intraorbitaler Fremdkörper durch MDCT. Fortschr Röntgenstr 2011; 183: $543-548$

5 Reiss-Zimmermann M, Sorge I, Sterker I et al. MRT-Bildgebung von Orbitaerkrankungen im Kindesalter. Fortschr Röntgenstr 2011; 183: $781-787$

6 Erb K, Bohner G, Mussler A. Anteriores Staphylom beim Neugeborenen. Fortschr Röntgenstr 2011; 183: 390 - 391

7 Bilaniuk LT, Schenck JF, Zimmerman RA et al. Ocular and orbital lesions: surface coil MR imaging. Radiology 1985; 156: 669-674

8 Sullivan JA, Harms SE. Surface-coil MR imaging of orbital neoplasms. Am J Neuroradiol 1986; 7: 29-34

9 Wilms G, Marchal G, Decrop E et al. Kernspinresonanztomographie der Orbita mit Teslagerät (1,5 Tesla). Fortschr Röntgenstr 1988; 149: 496 501

10 Mihara F, Murayama S, Gupta KL et al. Peripheral findings in MR using surface coil. Comput Med Imaging Graph 1991; 15: 451 -454

11 Hosten N, Lemke A, Sander B et al. MRT des Auges: Normalanatomie und Nachweis kleinster Läsionen mit einer hochauflösenden Oberflächenspule. Fortschr Röntgenstr 1996; 164: 126-131

12 Lemke AJ, Hosten N, Grote A et al. Anatomie und Pathologie des Retrobulbärraums in der MRT bei Anwendung einer hochauflösenden Oberflächenspule. Ophthalmologe 1996; 93: 292 - 298

13 Georgouli T, Chang B, Nelson M et al. Use of high-resolution microscopy coil MRI for depicting orbital anatomy. Orbit 2008; 27: 107-114

14 Rossi C, Boss A, Lindig TM et al. Diffusion-Tensor-Bildgebung des Rückenmarks bei 1,5 und 3,0 Tesla. Fortschr Röntgenstr 2007; 179: 219224

15 Regier M, Nolte-Ernsting C, Adam $G$ et al. Intraindividueller Vergleich der Bildqualität in der MR-Urographie bei 1,5 und 3 Tesla am Tiermodell. Fortschr Röntgenstr 2008; 180: 915-921

16 Rottgen R, Haltaufderheide K, Schroder RJ et al. Auswirkung der Feldstärke bei der standardisierten Kernspintomographie des Gehirns am Beispiel der Darstellung von Hirnnerven und Gefäßen in den basalen Zisternen: Vergleich zwischen 1,5 und 3,0 Tesla. Fortschr Röntgenstr 2005; 177: 530-535

17 Graf H, Schick F, Claussen CD et al. MR-Bildgebung der Innenohrstrukturen: Vergleich der hochaufgelösten Messung bei 1,5 $\mathrm{T}$ und $3 \mathrm{~T}$. Fortschr Röntgenstr 2004; 176: 17-20

18 Kuo R, Panchal M, Tanenbaum L et al. 3.0 Tesla imaging of the musculoskeletal system. J Magn Reson Imaging 2007; 25: 245-261

19 Mafee MF, Rapoport M, Karimi A et al. Orbital and ocular imaging using 3- and 1.5-T MR imaging systems. Neuroimaging Clin N Am 2005; 15 : $1-21$

20 Lemke AJ, Alai-Omid M, Hengst SA et al. Eye imaging with a 3.0-T MRI using a surface coil - a study on volunteers and initial patients with uveal melanoma. Eur Radiol 2006; 16: 1084 - 1089

21 Sanchez I, Martin R, Ussa F et al. The parameters of the porcine eyeball. Graefes Arch Clin Exp Ophthalmol 2011; 249: 475-482

22 Dietrich O, Raya JG, Reeder SB et al. Measurement of signal-to-noise ratios in MR images: influence of multichannel coils, parallel imaging, and reconstruction filters. J Magn Reson Imaging 2007; 26: 375- 385

23 Vogel H. Maße in der Sonographie und in der Computertomographie. ecomed 1986

24 Merkle EM, Dale BM, Paulson EK. Abdominal MR imaging at 3T. Magn Reson Imaging Clin N Am 2006; 14: 17-26 
25 Tanitame K, Sone T, Kiuchi $Y$ et al. Clinical applications of high-resolution ocular magnetic resonance imaging. Jpn J Radiol 2012; 30: 695705

26 Obata T, Uemura $\mathrm{K}$, Nonaka $\mathrm{H}$ et al. Optimizing T2-weighted magnetic resonance sequences for surface coil microimaging of the eye with regard to lid, eyeball and head moving artifacts. Magn Reson Imaging 2006; 24: $97-101$
27 Langner S, Martin H, Terwee T et al. 7.1 T MRI to assess the anterior segment of the eye. Invest Ophthalmol Vis Sci 2010; 51: 6575-6581

28 Richdale K, Wassenaar P, Teal BluesteinK et al. 7 Tesla MR imaging of the human eye in vivo. J Magn Reson Imaging 2009; 30: 924-932

29 Christoforidis JB, Wassenaar PA, Christoforidis GA et al. Retrobulbar vasculature using 7-T magnetic resonance imaging with dedicated eye surface coil. Graefes Arch Clin Exp Ophthalmol 2013; 251: 271 - 277 